\title{
Nutritional assessment of adult patients suffering from gout visiting tertiary care hospitals, Lahore
}

\author{
Safia Mazhar ${ }^{1}$, Aniqa Amjad ${ }^{1}$, Sidra Khalid ${ }^{1}$, Tahreem Nisar ${ }^{1}$, \\ Muhammad Nadeem ${ }^{2 *}$, Ammara Ameer ${ }^{3}$ and Ghulam Mueen-ud-Din ${ }^{1}$ \\ 1. University Institute of Diet and Nutritional Sciences, Faculty of Allied Health Sciences, University of Lahore- \\ Pakistan \\ 2. Institute of Food Science and Nutrition, University of Sargodha, Sargodha-Pakistan \\ 3. Department of Animal Resources, College of Life \& Natural Sciences, Daegu University Jillyang, Gyeongsan, \\ Gyeongbuk, 38453-South Korea \\ *Corresponding author's email: mnadeemft@gmail.com
}

Citation

Safia Mazhar, Aniqa Amjad, Sidra Khalid, Tahreem Nisar, Muhammad Nadeem, Ammara Ameer, Ghulam Mueenud-Din. Nutritional assessment of adult patients suffering from gout visiting tertiary care hospitals, Lahore. Pure and Applied Biology. Vol. 9, Issue 2, pp1568-1575. http://dx.doi.org/10.19045/bspab.2020.90164

\begin{tabular}{llll}
\hline \hline Received: 16/12/2019 & Revised: 26/02/2020 & Accepted: 05/03/2020 & Online First: 16/03/2020 \\
\hline \hline
\end{tabular}

\section{Abstract}

The research was aimed to determine the nutritional status and dietary behavior practice among adults suffering from gout. Gout is an arthritic disease which arises when increase amount of uric acid (a normal waste product) deposits in the body, and monosodium urate crystals accumulate in the joints. A cross-sectional study was carried out at the medical and surgical department of Sir Ganga Ram Hospital and University of Lahore Hospital, Lahore during Dec-2017 to March-2018. Total 100 samples of gout were selected through non-probability convenient sampling technique. Patients were assessed through pre-tested questionnaire. SPSS version 21.0 was used for data analysis. Gout was more prevalent among 51 to 60 -year-old patients in both males and female. $50 \%$ patients were overweight, $74 \%$ were lightly active with $56 \%$ having low socio-economic status and $33 \%$ belonged to rural areas. Signs and symptoms observed were body pain, inflammation, pale skin and eyes. It was concluded that long term medication intake, complication like diabetes, hypertension, kidney disease and heart disease, absence of physical activity, dehydration were risk factors of gout. According to current study, more consumption of meat, legumes, dessert, carbonated beverages and soft drink leads to gout spasm.

Keywords: BMI; Dietary factor; Gout; Joint; Serum; Uric acid

\section{Introduction}

Gout is an arthritic disease which arises when increased amount of uric acid (a normal waste product) deposits in the body, and monosodium urate crystals accumulate in the joints [1]. In acute gouty arthritis patient feel pain and joint swelling during gout attacks, when the severity and period of acute attacks raise for long time that cause chronic gout, which may be related with accumulation of uric acid crystals called as tophi [2]. Major etiological factor of gout is hyperuricemia (elevated high levels of blood uric acid). Some studies also showed that hyperuricemia is associated with CVD and neurological diseases [3]. Some dietary factors raise the 
risk of incident gout such as seafood intake and meat intake. Diet which is associated with a lower risk of incident gout and lower rate of gout flares is folate intake and coffee consumption. Alcohol increased the risk of incident gout, especially hard liquor and beer. Higher risks of gout attack were associated with loop diuretics and Thiazide. Diabetes, renal insufficiency, obesity, hypertriglyceridemia, Hypertension and hypercholesterolemia are diseases which are related with increased risk of incident gout [4]. High amounts of fructose containing sugar-sweetened soft drinks remarkably increased serum uric acid levels and the risk of gout [5]. Some researchers have shown that skim milk (non- fat milk) has effective role in prevention of gout and has property to lower $10 \%$ serum uric acid in individuals [6]. Gout is usually most common in men [7]. Gout also affects young women but mostly develop in women who are more likely to be over the age of 50, have other diseases and be on diuretics [8]. Some studies show that gout is mostly associated with family history of gout. Mostly $90 \%$ of disease is genetic, while other $10 \%$ is lifestyle disease. Gout remains untreatable until main genetic factor is not targeted in patients [9]. Gout and hyperuricemia have both non-modifiable and modifiable risk factors. Age and sex are nonmodifiable health hazards. Modifiable risk factor for gout includes obesity, the use of certain medications, high purine intake and consumption of purine-rich alcoholic beverages [10]. The global ratio of gout is widespread and appears to be raising over the past 50 years in many parts of the world. Across the globe distribution of gout is unequal, hence Pacific countries being the highest in incidence. Burden of gout tend to have higher in industrialized countries than in developing countries. Some ethnic groups are particularly susceptible to gout, supporting the importance of genetic factor [11]. During earlier year's gout has been included in global burden of disease. Globally prevalence of gout was increased $(0.08 \%)$. Gout has been ranked as 173 in terms of overall burden. The globally burden of gout is rising due an increase in ageing population [12]. The prevalence of gout in Pakistan (Karachi) was higher in male than female. Prevalence of gout was high in patients that are above 50 years of age. Gout arthritis is related with several factors that are becoming so much prevalent which are CKD, metabolic syndrome, and cardiovascular disease [13]. Gout can be cured by following two rules first is treatment of the acute gout attack, to decrease pain and debility and treatment of hyperuricemia by lifestyle adjustment and second with usage of urate lowering medications. Ideal serum uric level which should be achieved during management of gout should be less than 6 $\mathrm{mg} / \mathrm{dl}$ [14]. A study was conducted to evaluate associations of BMI, diet, physical activity on risk of gout attacks in seemingly healthy and strongly active men. Total 28990 men self-reported gout were contrast with BMI, normal and highly physical activity. Result showed that risk of gout raise with BMI (1.19\%), alcohol intake $(1.19 \%)$ meat consumption $(1.45 \%)$ and decreased with consumption of fruit $(0.73 \%)$ and in runners $(0.55 \%)$. Elevated level of BMI increases risk of gout while lower BMI decreases risk of gout, while compared with less active with highly active individual who ran more than 8 kilometers a day had 50 to $65 \%$ decreased risk of gout [15]. The cross sectional study was conducted to evaluate the difference in uric acid level among people who eat vegans, meat, vegetarian and fish. Total 1693 peoples were selected in which 670 was men and other 1023 was women. Test of uric acid were assessed. Diet history was evaluated by asking food frequency questionnaire. Their result demonstrates that Participants who eat a vegan diet had the peak level of uric acid related to meat eaters, fish eaters and 
vegetarians, and other individuals had the lowest amount of serum uric acid, who don't eat meat but consume vegetarians and fish. The serum amount of uric acid was significantly increased in men than woman [16].

The researcher was aimed to determine the nutritional status and dietary behavior practice among adults suffering from gout. After assessment of nutritional status and dietary behavior, awareness may be created among adults to improve the dietary choices, throughout extensive health education. Mortality and complications due to gout may be reduced. As if left untreated it will affect quality of life among adults and increases economic burden on society.

\section{Materials and methods}

A cross-sectional study was carried out at the medical and surgical department of Sir Ganga Ram Hospital and University of Lahore Hospital, Lahore during Dec-2017 to March-2018. Total 100 samples of gout were selected through non-probability convenient sampling technique. Inclusion criteria were indoor and outdoor adult patients of both genders suffering from gout and exclusion criteria were adult patients not suffering from gout and non-cooperative patients. The rules and regulations of ethical committee of University of Lahore were followed while conducting the research. Written informed consent was taken from all the patients. After taking informed written consent, data were collected with the help of pre-tested data collection tool (Questionnaire/Pro-forma). Patients were assessed through pre-tested questionnaire. Statistical Package for the Social Sciences (SPSS) version 21.0 was used for data analysis.

\section{Results}

Results showed that $8 \%$ patients were of age between 21-30 years, $20 \%$ patients were 31 40 years, $19 \%$ patients were $41-50$ years and the prevalence of gout was high in patients with age of 51-60 years as shown in the (Fig
1). $16 \%$ patient's age was $61-70$ years. $6 \%$ patient's age was 71-80 years. 3\% patient's age was $81-90$ years. $1 \%$ patient's age was 91-100 years.

The results showed that, majority $50 \%$ patients were overweight and 33\% were obese. $2 \%$ were underweight and $15 \%$ were of normal weight as shown in the (Fig 2).

$36 \%$ of patients have hypertension where as $64 \%$ of patients not have hypertension as shown in (Fig. 3).

Out of 100 participants, $46 \%$ were not consuming red meat at all, $11 \%$ patients were consuming red meat 1-2 times per week, $2 \%$ patients were consuming red meat 3-2 times per week and $41 \%$ were consuming red meat once a week (Table 1).

$8 \%$ patients never consumed fruits at all but $6 \%$ patients were consuming fruits on daily basis, $30 \%$ patients were consuming fruits 1 2 times per week, $4 \%$ were consuming fruits 3-4 times per week and only $52 \%$ patients were consuming fruits once a week (Fig. 4).

\section{Discussion}

Current findings showed that $50 \%$ patients were overweight, $33 \%$ were obese, $15 \%$ were of normal weight while $2 \%$ were underweight. Choi et al. determine the effect of diuretic use, weight change, hypertension, obesity, and risk of gout. A cross-sectional study was conducted during 2005, which included 47150 participants. Data were collected randomly through questionnaire. Among participant 730 were assessed with gout according to ranges of BMI. The risk was $1.95 \%$ individuals with 21 to 22.9 and BMI with 25 to $29.9,2.33$ and 30 to 34.9. The risk was $2.97 \%$. Men using diuretic medication and hypertension risk were $2.31 \%$. The burden of gout increased due to obesity, hypertension and weight change [17]. Similar results revealed by study conducted in Washington Country, Maryland to assess the gout association with obesity at younger age [18]. A study was conducted in 2010 to determine the association of body fat 
with metabolic syndrome gout. The result of study demonstrated that gout patients mean age were 42 and mean serum uric acid ranges were $9.0 \mathrm{mg} / \mathrm{dl}$. The most likely BMI of patients were $25.4-3.5 \mathrm{~kg} / \mathrm{m}^{2} .44 .4 \%$ patients were overweight and $25.6 \%$ were obese [19].

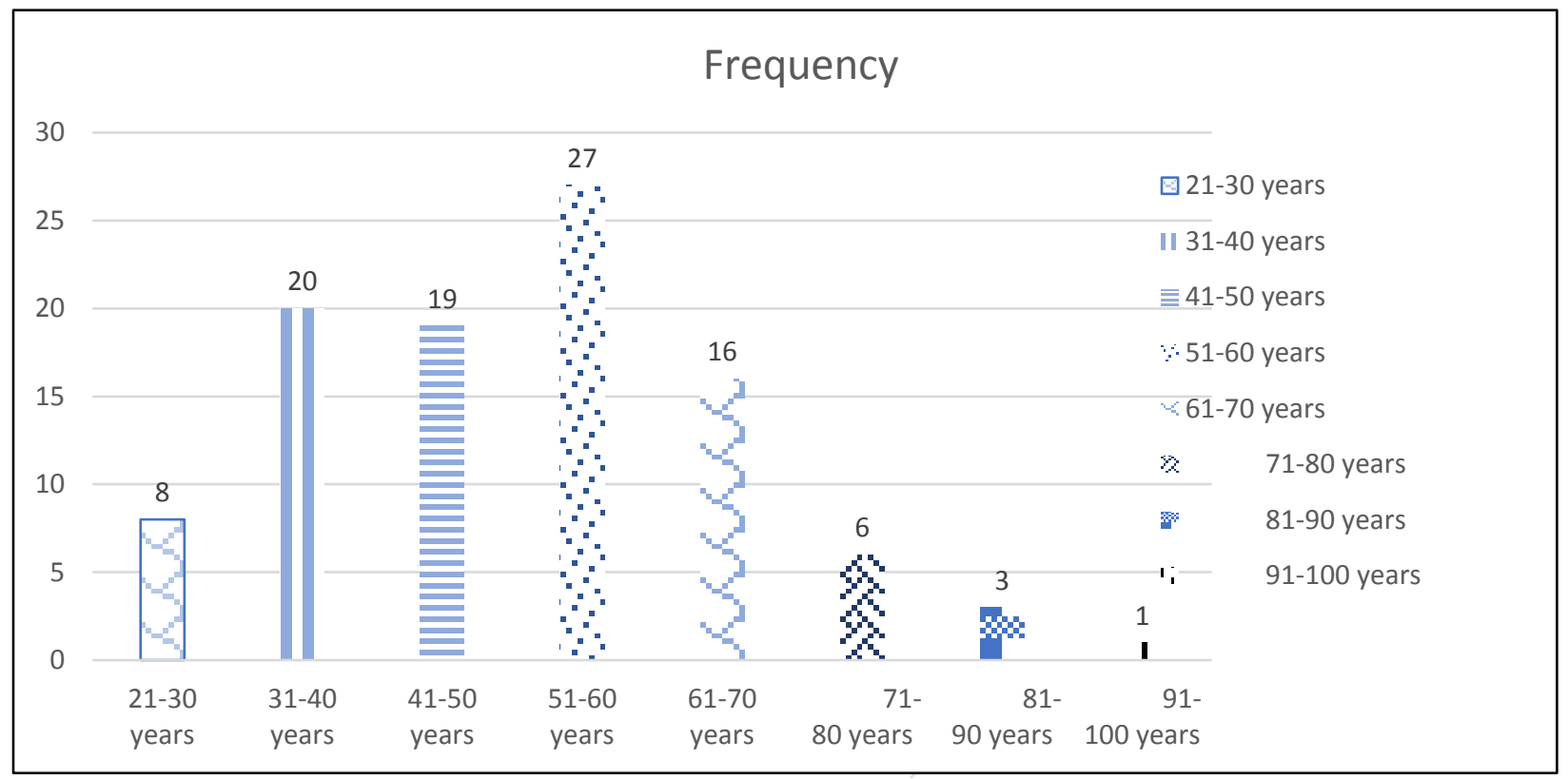

Figure 1. Frequency distribution of patients' age

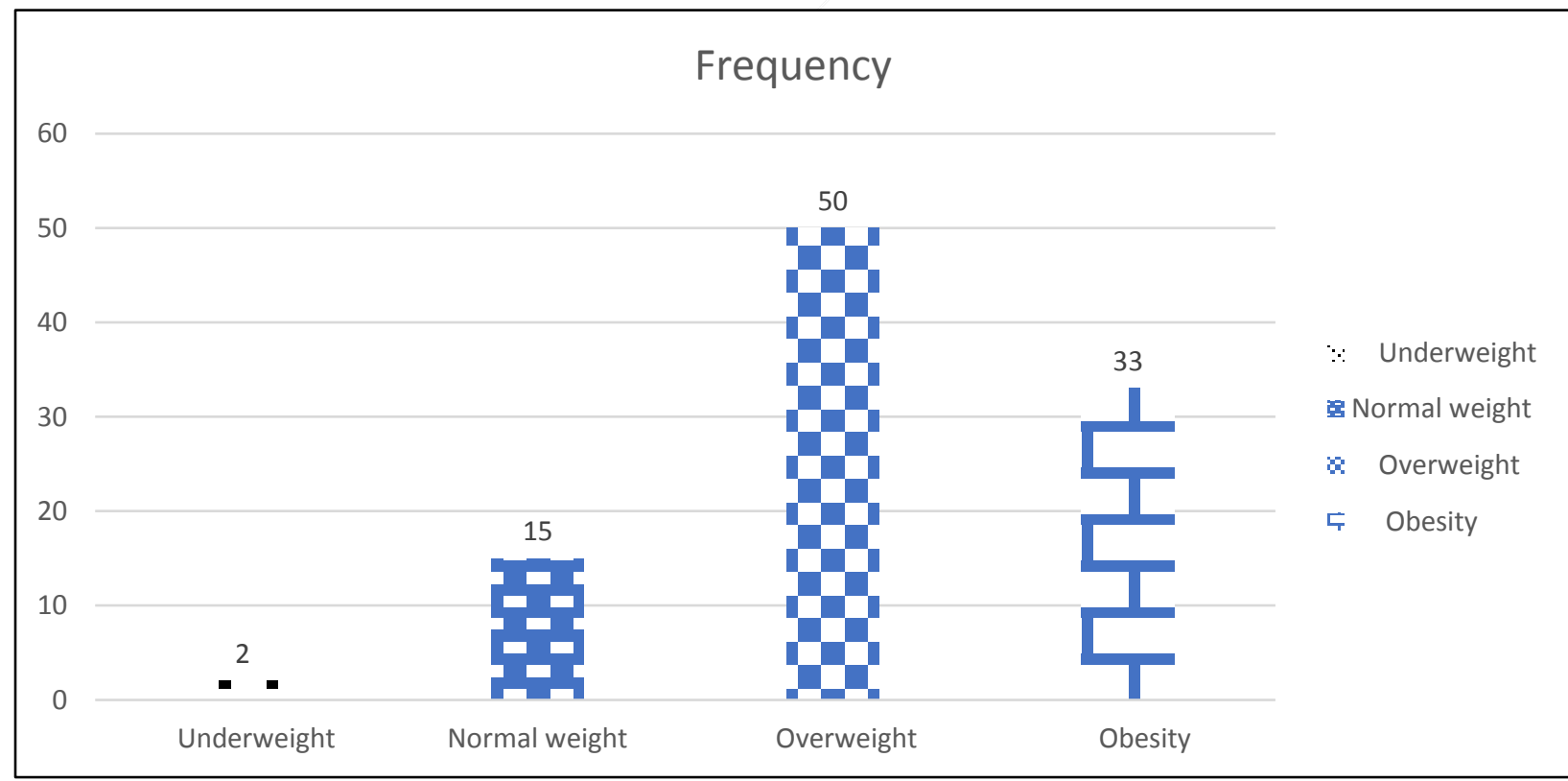

Figure 2. Frequency distribution of body mass index (BMI) 


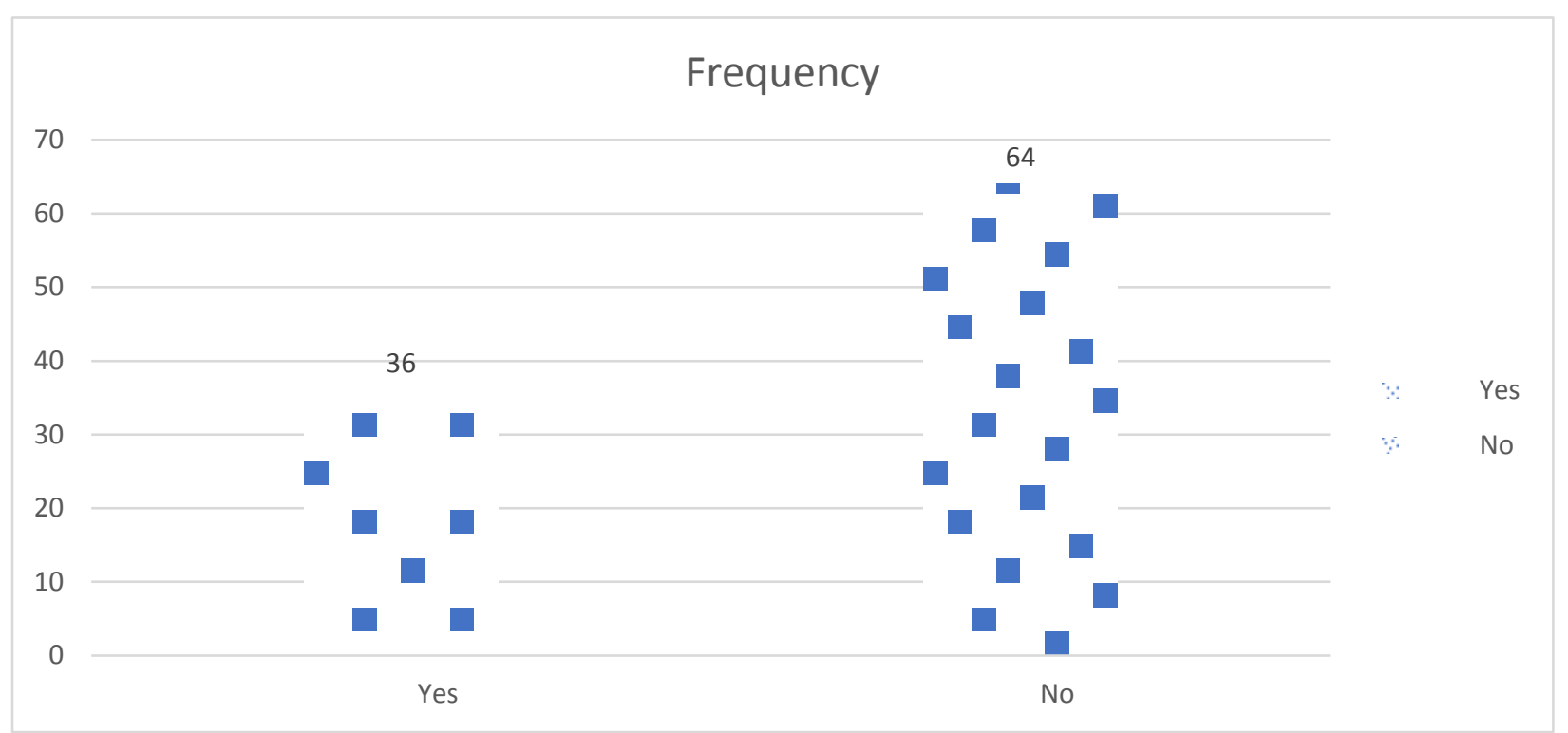

Figure 3. Frequency of hypertension in gout patients

Table 1. Frequency of meat consumption

\begin{tabular}{|c|c|c|c|c|c|c|}
\hline \multirow{2}{*}{$\begin{array}{c}\text { Uric } \\
\text { acid }\end{array}$} & $\begin{array}{c}1-2 \\
\text { times/ per week }\end{array}$ & $\begin{array}{c}\text { 3-4 } \\
\text { times/per } \\
\text { week }\end{array}$ & $\begin{array}{c}\text { Once a } \\
\text { week }\end{array}$ & Never & Total & \multirow{2}{*}{ P - value } \\
\cline { 2 - 6 } $\begin{array}{c}3.5-7.0 \\
\text { mg/dl }\end{array}$ & 2 & 1 & 28 & 29 & 60 & \\
\cline { 2 - 7 } $\begin{array}{c}7.1-14.0 \\
\text { Total }\end{array}$ & 11 & 1 & 13 & 17 & 40 & \\
\cline { 2 - 7 } & 9 & 2 & 41 & 46 & 100 & 0.002 \\
\hline
\end{tabular}

\section{Frequency}

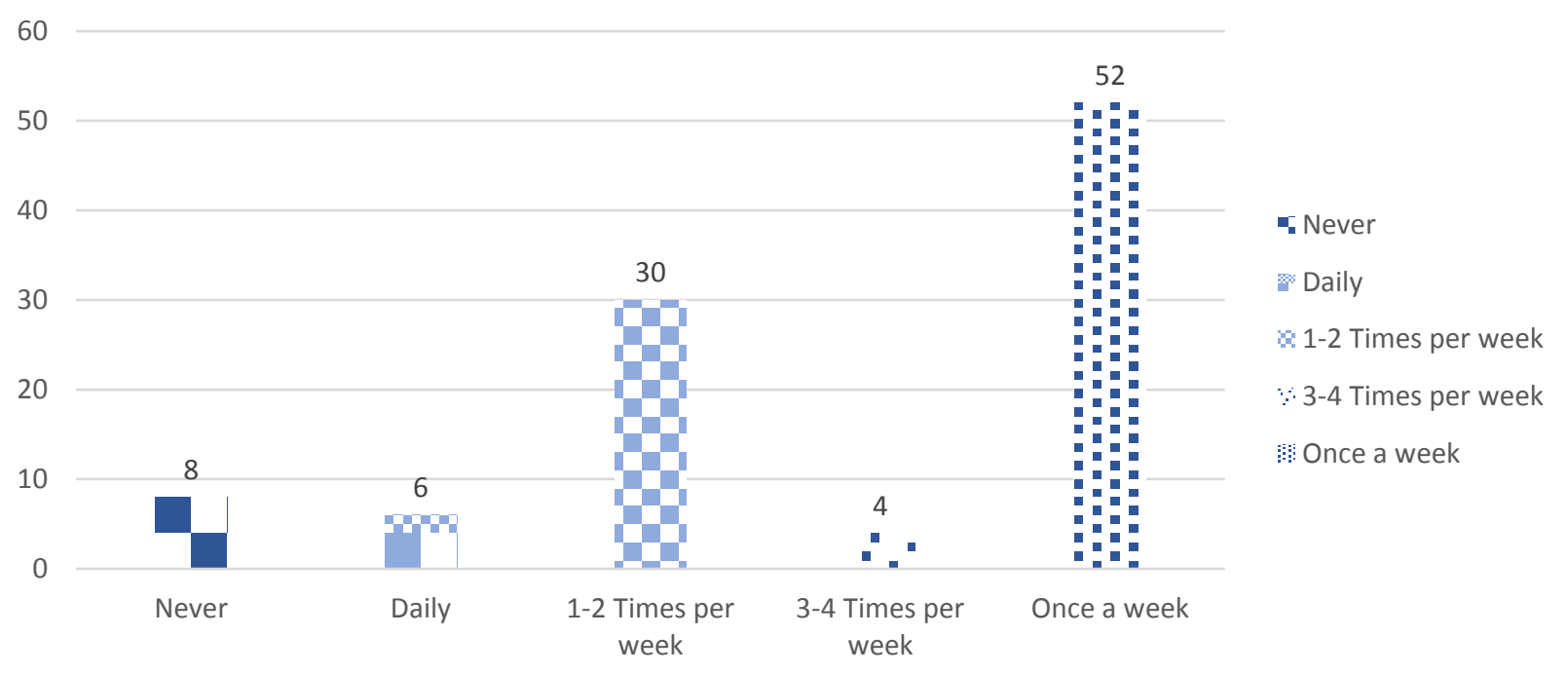

Figure 4. Frequency distribution of Fruits Consumption 
Current research found that $36 \%$ of patients have hypertension, whereas $64 \%$ of patients not have hypertension. Hypertension is linked with gout which is also studied to observe the relationship of DASH diet and serum Uric acid level. The result concluded that DASH diet helps in decreasing the serum uric acid. The data were randomly analyzed in pre HTN and HTN patients. DASH diet was measured 30 to 90 day and results were compared with baseline SUA level. DASH diet decreased SUA 0.8 and $1.0 \mathrm{mg}$ dl [20]. A study was conducted to examine the association of blood pressure and biochemical parameters in both male and female patients with gout. Result showed that diastolic BP was higher in male patients than female [21]. Another study revealed that gout has important relationship with hypertension. Hypertension is more common comorbidities of gout [22].

Findings of current study revealed that $46 \%$ were not consuming red meat at all, $11 \%$ patients were consuming red meat 1-2 times per week, $2 \%$ patients were consuming red meat 3-2 times per week and $41 \%$ were consuming red meat once a week. A case control study was conducted in Chinese adult to determine the relation of dietary pattern and recently identified hyperuricemia. Total 14538 individuals were included in study. 1422 participants were generated as cases and 1422 as controls. Dietary consumption was evaluated by using self-made food frequency questionnaire. Three dietary groups were made by factor analysis. First group was sweet pattern, second was animal and $3^{\text {rd }}$ was vegetable. In recently identified hyperuricemia animal dietary pattern was having the highest value 1.50 while other two patterns (plant \& vegetable) were not identified in recently developed hyperuricemia. In Chinese population animal dietary pattern (meat products, organ meat and seafood) effectively increased hyperuricemia [23]. Another study revealed that low purine diet with medication allopurinol is helpful in lowering serum uric acid as compared to purine diet $[\mathbf{2 4}, \mathbf{2 5}]$.

$8 \%$ patients never consumed fruits at all but $6 \%$ patients were consuming fruits on daily basis, $30 \%$ patients were consuming fruits 1 2 times per week, $4 \%$ were consuming fruits 3-4 times per week and only 52\% patients were consuming fruits once a week. Similar study revealed that Orange juice has healthy effect and have important role in decreasing serum uric acid from body [26]. Similar result were found by survey in 2012, among individuals with gout to observe the association of cherry intake with risk of repeated gouty spasm The result shows that cherry consumption decrease $35 \%$ risk of gout distress in participants [27]. Results of current study revealed that $20 \%$ participants were not consuming yogurt, only $10 \%$ were consuming yogurt on daily basis and only $24 \%$ were consuming 1-2 times per week, $21 \%$ consuming 3-4 times per week and $25 \%$ were consuming yogurt once a week . The results current study were similar to the previous findings revealed that two groups were consuming yogurt for 3 days $1^{\text {st }}$ group was taking $112 \mathrm{~g}$ while other was taking $498 \mathrm{~g}$ which were helpful in lowering serum uric acid [28].

\section{Conclusion}

Study concluded that the risks factors of gout were more apparent in female patients than in male. Inheritance of gout was more common risk factors in patients. Age group of 51-60 years was at higher risk of developing gout. Illiteracy, low socioeconomic status of patients, overweight, long term medication intake and complication like diabetes, hypertension, kidney disease and heart disease in patients were also the risks factors of gout. Excessive intake of meat, eggs, legumes, dessert, carbonated beverages and soft drinks and low water intake may increase gout attacks. Majority of patients were not 
consuming fruits, fruit shakes, milk, yogurt in their daily routine.

\section{Authors' contributions}

Conceived and designed the experiments: A Amjad, S Khalid, T Nisar \& M Nadeem, Performed the experiments: S Mazhar, Analyzed the data: A Amjad \& M Nadeem, Contributed materials/ analysis/ tools: S Mazhar, A Amjad, S Khalid, T Nisar, A Ameer \& GM Din, Wrote the paper: S Mazhar, A Amjad \& M Nadeem.

\section{References}

1. Hinds K (2011). What is Gout? U: The Caribbean health digest. (13): 46-7.

2. Qaseem A, Harris RP \& Forciea MA (2017). Management of acute and recurrent gout: a clinical practice guideline from the American College of Physicians. Ann Intern Med 166(1): 5868.

3. Jin M, Yang F, Yang I, Yin Y, Luo JJ, Wang H \& Yang XF (2012). Uric acid, hyperuricemia and vascular diseases. Frontiers in Biosci 1: 17:656.

4. Singh JA, Reddy SG \& Kundukulam J (2011). Risk factors for gout and prevention: a systematic review of the literature. Mar 23(2): 192.

5. Choi JW, Ford ES, Gao X \& Choi HK (2008). Sugar-sweetened soft drinks, diet soft drinks, and serum uric acid level: The third national health and nutrition examination survey. Arthritis Rheum 59(1): 109-116.

6. Dalbeth N, Wong S, Gamble GD, Horne A, Mason B, Pool B, Fairbanks L, McQueen FM, Cornish J, Reid IR \& Palmano K (2008). Acute effect of milk on serum urate concentrations: a randomised controlled crossover trial. Ann Rheum Dis 59(1): 109-16.

7. Singh JA (2013). Racial and gender disparities among patients with gout. Current Rheumatol Rep 15(2): 307.

8. Kumar S, Gupta R \& Suppiah R (2012). Gout in women: differences in risk factors in young and older women. The New Zealand Med J 12: 125(1363).

9. Jefferson W (2014). Understanding Gout. Healthy Living Publications; Oct 8.

10. Saag KG \& Choi H (2006). Epidemiology, risk factors, and lifestyle modifications for gout. Arthritis Res Ther (1): S2.

11. Kuo CF, Grainge MJ, Zhang W \& Doherty M (2015). Global epidemiology of gout: prevalence, incidence and risk factors. Nat Rev Rheumatol (11): 649.

12. Smith E, Hoy D, Cross M, Merriman TR, Vos T, Buchbinder R, Woolf A \& March L (2014). The global burden of gout: Ann Rheum Dis 73(8): 1470-1476.

13. Akram M, Usmanghani K, Akhtar N, Shah PA, Saeed T, Jabeen Q, Asif HM, $\&$ Shah SA (2011). Prevalence of gout in Gadap town, Karachi community, Pakistan. Afr J Biotechnol 10(40): 78937895.

14. Gröbner W \& Walter-Sack (2005). Treatment of hyperuricemia and gout. Medizinische Monatsschrift fur Pharmazeuten 28(5): 159-164.

15. Williams PT (2008). Effects of diet, physical activity and performance and body weight on incident gout in ostensibly healthy, vigorously active men. Am J Clin Nutr 87(5): 1480-1487.

16. Schmidt JA, Crowe FL, Appleby PN, Key TJ \& Travis RC (2013). Serum uric acid concentrations in meat eaters, fish eaters, vegetarians and vegans: a crosssectional analysis in the EPIC-Oxford cohort. PloS One 8(2): e56339.

17. Choi HK, Atkinson K, Karlson EW \& Curhan G (2005). Obesity, weight change, hypertension, diuretic use, and risk of gout in men: the health professional's follow-up study. Arch Intern Med 165(7): 742-748.

18. McAdams DeMarco MA, Maynard JW, Huizinga MM, Baer AN, Köttgen A, 
Gelber AC \& Coresh J (2011). Obesity and younger age at gout onset in a community-based cohort. Arthritis Care Res 63(8): 1108-1114.

19. Liang JJ, Ao ST, Li QH, Xu YH, Du XY, Yang KM, Lin JZ, Mo YQ \& Dai L (2018). Higher body fat is an independent risk factor for metabolic syndrome in gout. AB1032.

20. Tang O, Miller ER, Gelber AC, Choi HK, Appel LJ \& Juraschek SP (2017). DASH diet and change in serum uric acid over time. Clin Rheumatol 36(6): 1413-1417.

21. Bahorun T, Luximon-Ramma A, Gunness TK, Sookar D, Bhoyroo S, Jugessur R, Reebye D, Googoolye K, Crozier A \& Aruoma OI (2010). Black tea reduces uric acid and C-reactive protein levels in humans susceptible to cardiovascular diseases. Toxicol 278(1): 68-74.

22. Belovol AN, Knyazkova II \& Miroshnykova IA (2015). Gout and Hypertension. Likars' Ka Sprava (1-2): 32-38.

23. Xia Y, Xiang Q, Gu Y, Jia S, Zhang Q, Liu L, Meng G, Wu H, Bao X, Yu B \& Sun $S$ (2018). A dietary pattern rich in animal organ, seafood and processed meat products is associated with newly diagnosed hyperuricaemia in Chinese adults: a propensity score-matched casecontrol study. British J Nutr 119(10): 1177-1184.
24. Schiavo L, Favrè G, Pilone V, Rossetti G, De Sena G, Iannelli A \& Barbarisi A (2018). Low-purine diet is more effective than normal-purine diet in reducing the risk of gouty attacks after sleeve gastrectomy in patients suffering of gout before surgery: a retrospective study. Obesity Surgery 28(5): 12631270.

25. Mehmood A, Zhao L, Wang C, Nadeem N, Raza A, Ali N \& Shah AA (2019). Management of hyperuricemia through dietary polyphenols as a natural medicament: A comprehensive review. Crit Rev Food Sci 59(9): 1433-1455.

26. Büsing F, Hägele FA, Nas A, Döbert LV, Fricker A, Dörner E, Podlesny D, Aschoff J, Pöhnl T, Schweiggert R \& Fricke WF (2018). High intake of orange juice and cola differently affects metabolic risk in healthy subjects. Clinical Nutrition.

27. Zhang Y, Neogi T, Chen C, Chaisson C, Hunter DJ \& Choi HK (2012). Cherry consumption and decreased risk of recurrent gout attacks. Arthritis Rheumatol 64(12): 4004-4011.

28. Kurajoh M, Moriwaki Y, Koyama H, Tsuboi H, Matsuda H, Yamada N, Saito C, Kano H, Asami Y \& Yamamoto T (2018). Yogurt containing Lactobacillus gasseri PA-3 alleviates increases in serum uric acid concentration induced by purine ingestion: a randomized, doubleblind, placebo-controlled study. Gout Nucleic Acid Metabol 42(1): 31-40. 